\title{
The Prevalence rate of Hypertension in Rural Population of Bangladesh
}

\author{
Rahim MA ${ }^{1}$, Rahman $M M^{2}$, Rahman $M^{3}$, Ahmed $F^{4}$, Chowdhury $J^{5}$, Islam $F^{6}$ \\ ${ }^{1}$ Associate Professor, Department of Biochemistry, Northern Medical College, Rangpur, ${ }^{2}$ Lecturer, Department of Biochemistry, \\ Dhaka National Medical College, Dhaka, ${ }^{3}$ Professor, Department of Biochemistry, Satkhira Medical College, ${ }^{4}$ Professor, \\ Department of Paediatrics, Dinajpur Medical College, ${ }^{5}$ Assistant Professor, Department of Biochemistry, Somorita Medical \\ College, Dhaka, ${ }^{6}$ Senior Lecturer, Department of Biochemistry, Dhaka National Medical College, Dhaka.
}

\begin{abstract}
Background: The non-communicable diseases like hypertension, diabetes and asthma are emerging as a major health problem in Bangladesh. Recently, these are given high research priority by the Government of Bangladesh. The prevalence of hypertension is increasing rapidly, but there is no current study on prevalence of hypertension in rural population of Bangladesh.

There are some studies conducted on prevalence of hypertension from mid 70's to late 90's. Those studies showed the prevalence of hypertension is increasing significantly in both urban and rural population. In rural population the prevalence of hypertension was in $23.6 \%{ }^{1}$. After that there is no population based study was conducted on prevalence of hypertension in rural population of Bangladesh.

Methods:

We measured blood pressure, body weight and height of 532 individuals at and above the age of 20 years (age range 20-70 years) of both sexes accept pregnant and those who were under medication of hypertension. We collected information about smoking, family history of hypertension, status of physical activity, diabetes, annual income etc.
\end{abstract}

Result:

The overall prevalence rate of hypertension was $30.64 \%$ (male $31.53 \%$ and female $29.36 \%$ ). In the study, the blood pressure was measured in all study subjects. The mean blood pressure was higher in hypertensive participants than that of non hypertensive. The prevalence of hypertension $(\mathbf{3 0 . 6 4 \%})$ observed in this study was higher than the previous study. In this study showed that with the increasing age more the prevalence of hypertension. The similar funding also observed in recent Indian study. Our study showed that the hypertension prevalence was high among people with high BMI and obesity, positive family history, smoking and less physical activity.

Conclusion:

The prevalence of hypertension in the rural population was found to be on the increased compare to previous reports of Bangladesh and other Asian studies. Advanced age, obesity, higher incomes, family history of hypertension, smoking and reduced physical activity were proved significant risk factors for hypertension, whereas, sex, occupation, showed no association with hypertension.

Key Words: Hypertension, Diabetes Mellitus, Smoking, Physical activities. 


\section{Introduction:}

An epidemiological shift in the prevalence of hypertension in developing countries as compare to developed countries has been observed ${ }^{2,3}$. Studies from India and Bangladesh have shown upward trend in the prevalence of hypertension. The prevalence of hypertension has increased by 30 times among the urban population over period of 55 years and about 10 times the among rural population over a period of 36 years ${ }^{4}$.

Various hypotheses have been put forward to explain this rising trend and among these, consequence of urbanization such as change in life style pattern, diet and stress have been implicated. Dramatic changes in life style

from traditional to modern have lead to physical inactivity due to technological advances. Rising affluences has modified the dietary pattern characterized by increased consumption of diet rich in fat, sugar and calories

Furthermore, increasing population growth and technological advances have shrunken the employment opportunities particularly among the young generationleading to stress and hypertension in young person's including students and laborers ${ }^{5}$.

Developing counties are increasingly faced with the double burden of hypertension and other cardiovascular diseases along with infection and malnutrition ${ }^{3}$. Hypertension places an excessive financial burden on population and health systems, consuming scarce resources ${ }^{4}$. Population based preventive approaches are, thus, central for the management of hypertension in developing countries, where clinic-based care for complication is not feasible option.

\section{Research and Methods:}

A random sample of 532 rural individual (age $\geq 20$ years) were included in a cross-sectional study. We conducted this study in Jaldhaka upzilla under Nilphamari district, from the period of January 2008 to June 2008. The selected area is situated 325 kilometer away from Dhaka city. The total population of Jaldhaka Upzilla is $3,35,427$. The sociodemographic characteristics of rural life defined for this study were the livelihood primarily related to the agriculture activities.

\section{Data collection}

All male and female $\geq 20$ years of age were considered eligible except pregnant women and subjects on medication. The eligible participants were informed about the objectives of the study. After providing the informed consent, each interested individual was requested to attend the nearby health care center. Each participant's was interviewed for the status of physical activities, family history of hypertension, diabetes, smoking, annual income etc. The other investigations included anthropometry and blood pressure. Measurement of height, weight, waist and hip girth were taken with light cloth without shoes.

Diagnosis of hypertension was made by measurement of blood pressure in arm with sphygmomanometer according to the WHO diagnostic criteria.

\section{Diagnosis of hypertension (WHO criteria) \\ Grade 1 (mild) $=140-159 / 90-99 \mathrm{~mm}$ of $\mathrm{Hg}$ \\ Grade $2($ moderate $)=160-179 / 100-109 \mathrm{~mm}$ of $\mathrm{Hg}$ \\ Grade 3 (severe) $\quad=\geq 180 / \geq 110 \mathrm{~mm}$ of $\mathrm{Hg}$}

\section{Statistical Analysis}

All data was recorded systematically in a preformed data sheet and was analyzed by relevant statistical procedures with the windows software version 12.0.

The prevalence rates of hypertension were determined by simple percentage. Unpaired t-test, chi-square tests were done to see the level of significance. All associations were tested by co-relation coefficient (r). Binary logistic regression was used to quantify the individual risk prediction of hypertension with different independent risk factors. The risk factors were sex, family history, occupation, physically activity, annual income, obesity etc. All statistical test were considered significant at the level of $95 \%$ $(\mathrm{p}<0.05)$.

\section{Result}

Total 532 participants included in the study. Among them 314 were male and 218 female. Their mean \pm SD of age in years were $44.04 \pm 12.86$ and $42.91 \pm 12.59$ respectively. The age range was 20-70 years both in male and female. Table-I shows the characteristics of the study subjects.

Table-I: Characteristics of study subjects

\begin{tabular}{|c|c|c|c|c|c|c|}
\hline \multirow{2}{*}{$\begin{array}{c}\text { Total } \\
\text { study } \\
\text { subjects }\end{array}$} & \multicolumn{2}{|c|}{ Sex } & \multicolumn{2}{c|}{$\begin{array}{c}\text { Age (years) } \\
\text { Mean( }\end{array}$} & \multicolumn{2}{c|}{$\begin{array}{c}\text { Age range } \\
\text { (years) }\end{array}$} \\
\cline { 2 - 7 } & Male & Female & Male & Female & Male & Female \\
\hline $\mathrm{N}=532$ & 314 & 218 & $\begin{array}{c}44.04 \pm \\
12.86\end{array}$ & $\begin{array}{c}42.91 \pm \\
12.59\end{array}$ & $20-70$ & $20-70$ \\
\hline
\end{tabular}




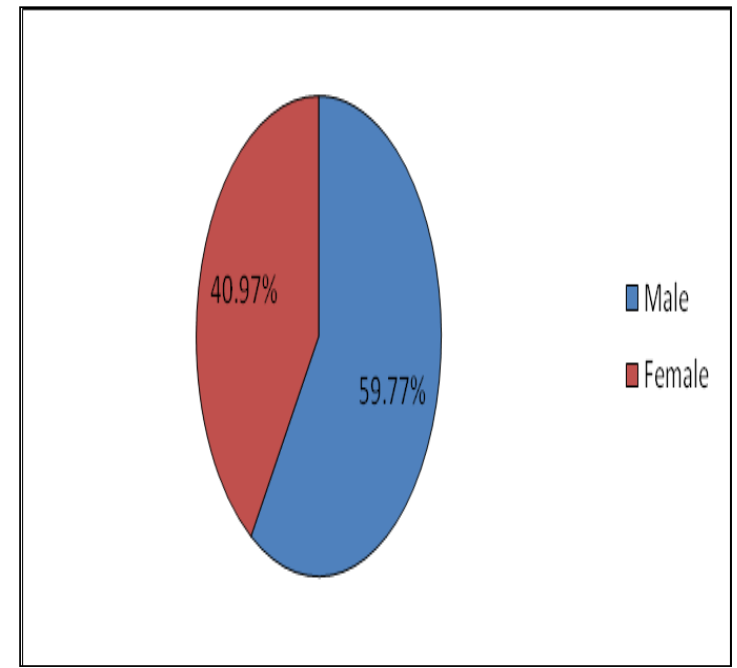

\section{Fig-1: Sex distribution of study subjects}

Table-II shows the frequency of hypertension and non hypertension in the study subject. Out of 532 study subjects, 163 were hypertension and 369 were non hypertension. Among the hypertension, 99 were male and 64 were female respectively.

Table-II: Frequency of hypertension and non hypertension in the study subjects

\begin{tabular}{|l|c|c|c|}
\hline \multicolumn{1}{|c|}{ Group } & Male & Female & Total \\
\hline Hypertension & 99 & 64 & 163 \\
\hline Non hypertension & 215 & 154 & 369 \\
\hline
\end{tabular}

Statistical analysis: Frequency distribution

Table-III shows the comparison of hypertension between male and female. There was no statistically significant difference between the two groups in both male and female ( $p>0.05)$.

Table-III: Comparison of sex in hypertension and non hypertension in the study subjects

\begin{tabular}{|l|l|l|l|c|}
\hline \multirow{2}{*}{ Group } & \multicolumn{2}{|c|}{$\begin{array}{c}\text { Sex of the study } \\
\text { subject }\end{array}$} & $\begin{array}{c}\text { Chi- } \\
\text { square } \\
\text { value }\end{array}$ & \multirow{2}{*}{ p-value } \\
\cline { 2 - 3 } & Male & Female & & \multirow{2}{*}{.28} \\
\hline Hypertension & 99 & 64 & $>0.05(.633)$ \\
\hline $\begin{array}{l}\text { Non } \\
\text { hypertension }\end{array}$ & 215 & 154 & & \\
\hline
\end{tabular}

Statistical analysis: Chi-square test

Table-IV shows the comparison of age in hypertension and non hypertension in the study subjects. Among the study subjects the hypertension patient's mean $\pm \mathrm{SD}$ of

age were $49.67 \pm 10.45$ and non hypertension participant's mean \pm SD of age were $40.88 \pm 12.75$. There was statistically significant difference in the mean \pm SD of age between the two groups $(\mathrm{p}<0.001)$.

Table-IV: Comparison of age (years) in hypertension and non hypertension in the study subjects

\begin{tabular}{|l|c|c|c|}
\hline \multicolumn{1}{|c|}{ Group } & $\begin{array}{c}\text { Mean } \pm \text { SD } \\
(\text { age in years })\end{array}$ & $\begin{array}{c}\text { t- } \\
\text { value }\end{array}$ & p-value \\
\cline { 1 - 2 } Hypertension & $49.67 \pm 10.45$ & -7.73 & $<0.001$ \\
\hline Non hypertension & $40.88 \pm 12.75$ & & \\
\hline
\end{tabular}

Statistical analysis: Unpaired "t" test

The mean $\pm \mathrm{SD}$ of blood pressure in hypertension (diastolic) patients was $97.48 \pm 7.50(\mathrm{mmofHg})$ and that of non hypertension were $73.68 \pm 7.83$ (mmofHg). There was statistically significant difference in the mean \pm SD of blood pressure between the two groups $(\mathrm{p}<0.001)($ Table-V).

Table-V: Comparison of hypertension $(\mathrm{mmol} / \mathrm{l})$ in between two groups of study subjects

\begin{tabular}{|l|c|c|c|}
\hline \multicolumn{1}{|c|}{ Group } & Mean \pm SD & t-value & p-value \\
\hline Hypertension & $97.48 \pm 7.50$ & \multirow{2}{*}{-32.75} & $<0.001$ \\
\cline { 1 - 2 } $\begin{array}{l}\text { Non } \\
\text { hypertension }\end{array}$ & $73.68 \pm 7.83$ & -35 & \\
\hline
\end{tabular}

Statistical analysis: Unpaired " $\mathrm{t}$ " test

The total study subjects were stratified in different age groups and prevalence of hypertension was observed in irrespective of sex distribution which shown in table -VI \& figure -2 .

Table-VI: Prevalence of hypertension in different age group of all study subjects

\begin{tabular}{|c|c|c|c|c|}
\hline $\begin{array}{c}\text { Age group } \\
\text { (years) }\end{array}$ & Hypertension & $\begin{array}{c}\text { Non } \\
\text { hypertension }\end{array}$ & Total & Percentage \\
\hline $20-30$ & 9 & 104 & 113 & $7.96 \%$ \\
\hline $31-40$ & 30 & 97 & 127 & $23.62 \%$ \\
\hline $41-50$ & 51 & 86 & 137 & $37.23 \%$ \\
\hline $51-60$ & 51 & 58 & 109 & $46.79 \%$ \\
\hline $61-70$ & 22 & 22 & 44 & $50.00 \%$ \\
\hline Total & 163 & 369 & 532 & $30.63 \%$ \\
\hline
\end{tabular}

Statistical analysis: Frequency distribution 


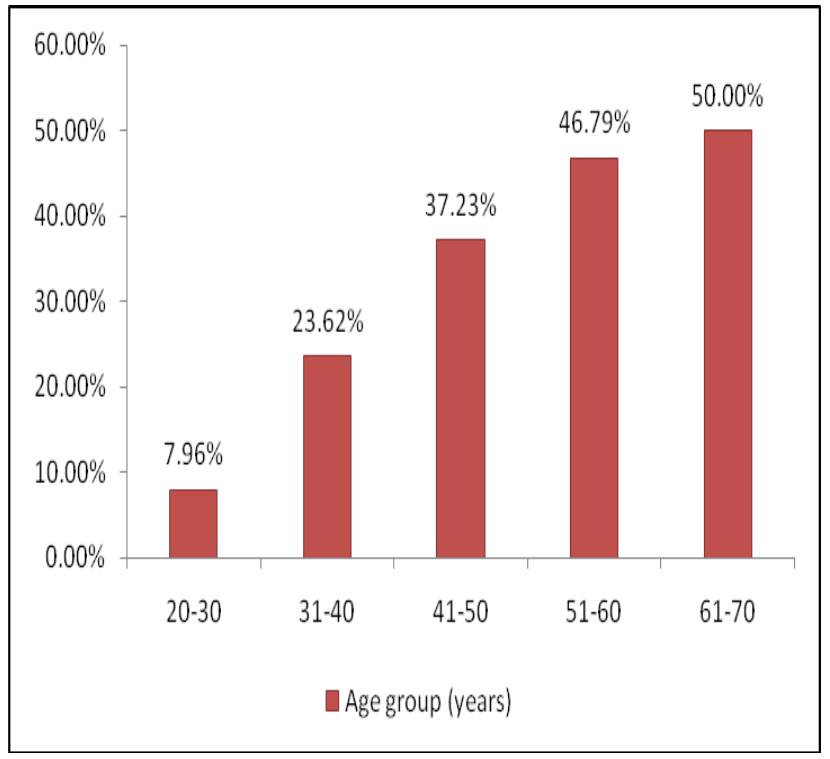

Fig-2: Prevalence of hypertension in different age group of all study subjects

Table-VII and figure -3 shows the prevalence of hypertension in all study subjects. Out of total 5302 study subjects, 163 were hypertensive and 369 were not. The prevalence rate of hypertension was $30.64 \%$ and non hypertension was $69.36 \%$.

Table-VII: Prevalence of hypertension in all study subjects

\begin{tabular}{|c|l|c|c|}
\hline $\begin{array}{c}\text { Total study } \\
\text { subjects }\end{array}$ & \multicolumn{1}{|c|}{ Group } & Frequency & Percentage \\
\hline \multirow{2}{*}{$\mathbf{N}=\mathbf{5 3 2}$} & Hypertension & 163 & $30.64 \%$ \\
\cline { 2 - 4 } & $\begin{array}{l}\text { Non } \\
\text { hypertension }\end{array}$ & 369 & $69.36 \%$ \\
\hline
\end{tabular}

Statistical analysis: Frequency distribution

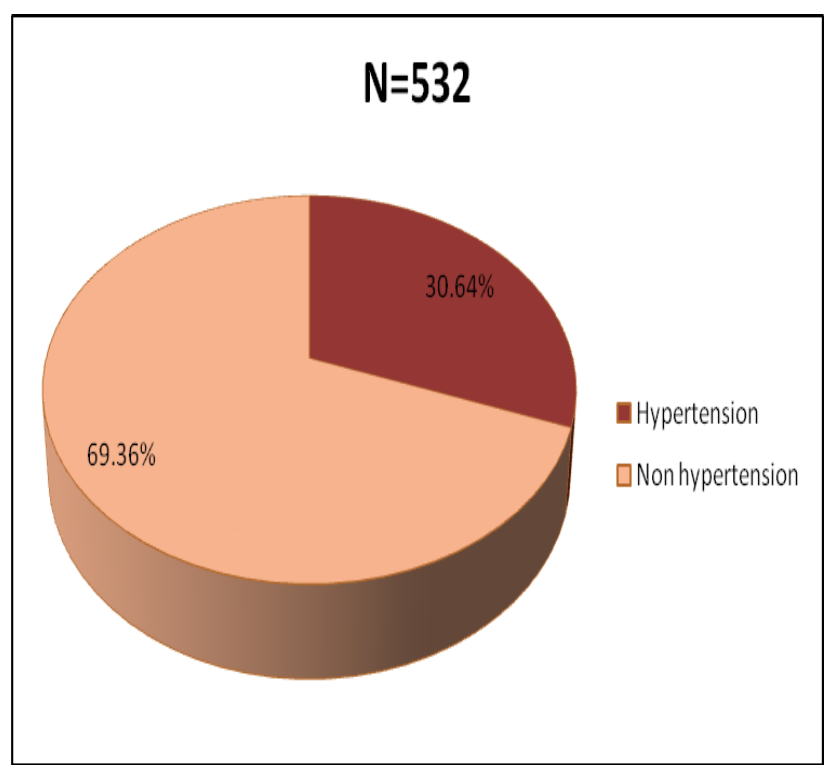

Fig-3: Prevalence of hypertension in all study subjects

Among the 532 study subjects, 314 were male and 218 were female. Out of 314 male, 99 were hypertensive and 215 were not. Out of 218 female, 64 were hypertensive and 154 were not.

The prevalence rate of hypertension in male and female was $31.53 \%$ and $29.36 \%$ respectively (TableVIII \& figure -4).

Table-VIII: Prevalence of hypertension in male and in female of all study subjects

\begin{tabular}{|c|c|c|c|c|}
\hline Sex & Hypertension & $\begin{array}{c}\text { Non } \\
\text { hypertension }\end{array}$ & Total & Percentage \\
\hline Male & 99 & 215 & 314 & $31.53 \%$ \\
\hline Female & 64 & 154 & 218 & $29.36 \%$ \\
\hline
\end{tabular}

Statistical analysis: Frequency distribution

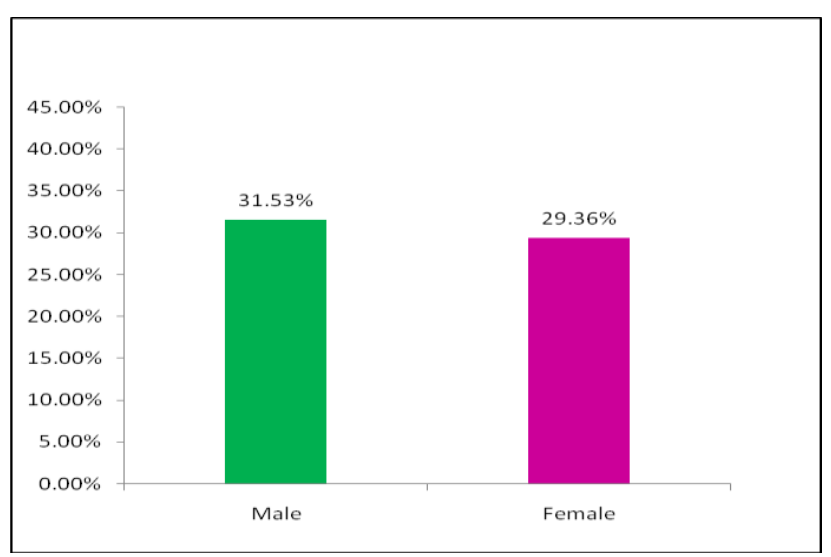

Fig-4: Prevalence of hypertension in male and in female of all study subjects

Table IX and figure- 5 shows the prevalence of systolic and diastolic hypertension of all study subjects. Total 532 participants 137 were systolic hypertension and 395 were not which was $25.8 \%$ and $74.2 \%$ respectively. Out of 532 study subjects, 163 were diastolic hypertension and 369 were not, which was $30.6 \%$ and $69.4 \%$ respectively.

Table-IX: Prevalence of systolic hypertension and diastolic hypertension of all study subjects

\begin{tabular}{|c|l|c|c|}
\hline $\begin{array}{c}\text { Total study } \\
\text { subjects }\end{array}$ & \multicolumn{1}{|c|}{ Group } & Frequency & Percentage \\
\hline \multirow{5}{*}{$\mathrm{N}=532$} & Systolic hypertension & 137 & $25.8 \%$ \\
\cline { 2 - 4 } & Non systolic hypertension & 395 & $74.2 \%$ \\
\cline { 2 - 4 } & Diastolic hypertension & 163 & $30.6 \%$ \\
\cline { 2 - 4 } & $\begin{array}{l}\text { Non diastolic } \\
\text { hypertension }\end{array}$ & 369 & $69.4 \%$ \\
\hline
\end{tabular}

Statistical analysis: Frequency distribution 


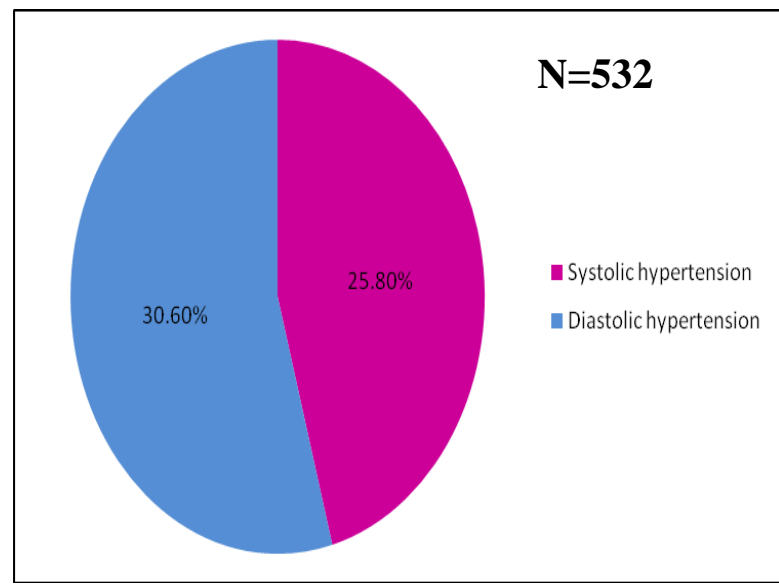

Fig-5: Prevalence of systolic hypertension and diastolic hypertension of all study subjects

Table-X examines the correlation of hypertension with sex, family history, occupation, physically activity, annual income, obesity and smoking of all study subjects. There was statistically significant association of hypertension with family history $(p<0.01)$, physically activity $(\mathrm{p}<0.01)$, annual income $(\mathrm{p}<0.01)$, smoking $(p<0.01)$, obesity $(p<0.01)$. But no statistically significant association of hypertension with occupation and sex was recognized.

Table-X: Correlation of hypertension with family history, smoking, occupation, physical activity, annual income, obesity, BMI, WHR, sex \& age of all study subjects

\begin{tabular}{|l|c|c|}
\hline $\begin{array}{c}\text { Correlation of } \\
\text { DM with }\end{array}$ & r-value & p-value \\
\hline Family history & -.228 & $<0.01$ \\
\hline Smoking & -.126 & $<0.01$ \\
\hline Income & -.131 & $<0.01$ \\
\hline Occupation & .009 & $>0.05$ \\
\hline Physical activity & -.141 & $<0.01$ \\
\hline Obesity & -.284 & $<0.01$ \\
\hline BMI & .276 & $<0.01$ \\
\hline WHR & -.124 & $<0.01$ \\
\hline Sex & -.023 & $>0.05$ \\
\hline Age & .286 & $<0.01$ \\
\hline
\end{tabular}

\section{Statistical analysis: Correlation coefficient (r) test}

\section{Discussion:}

In this cross-sectional study, our aim was to explore the prevalence of hypertension in the rural population of Bangladesh. The response was satisfactory. In our study, the blood pressure was measured in all study subjects. The mean blood pressure was statistically significantly higher in hypertension as compared with non hypertension (Table-V). The prevalence of hypertension $(30.64 \%)$ observed in this study was higher than the previous study ${ }^{\mathbf{1}}$. Hypertension is a major public health problem in Bangladesh, India and in other developing countries ${ }^{2,3}$. This is obvious from several Bangladesh and Indian urban and rural studies $\mathbf{4 , 6 , 7}$. Countries with an ageing population in developed countries will be expected to have a higher prevalence of hypertension than developing countries with a younger population's such as Bangladesh, India, but there are studies, which have documented a high prevalence rate of hypertension in developing countries $^{2,3}$.

Our study showed that with the increasing age progressively more subject with hypertension and that was similar findings with a recent Indian study ${ }^{\mathbf{8}}$.

In rural Bangladesh, road communication, electrification and mechanized cultivation in recent years has minimized physical activity. Average calori intake is also increased. These developmental changes have influenced the lifestyle of the rural people. In this study we observed that the prevalence rate of hypertension in male was $31.53 \%$ and in female was $29.36 \%$ respectively (Table-VIII). Though the prevalence rate was higher in male but there was no statistically significant difference between male and female.

Our study showed that the hypertension prevalence was high among people with high BMI and obesity. The similar finding also observed in different studies conducted in different rural area of India. In this study we also observed that high prevalence of hypertension of patients with positive family history, smoking and less physical activity.

It is observed that the prevalence of hypertension showed a moderate increased in the rural population of Bangladesh. Both male and female had equal risk of hypertension.

\section{Conclusion:}

The prevalence of hypertension in the rural population was found to be on the increased compare to previous reports of Bangladesh and other Asian studies. More studies are suggestive to evaluate the prevalence of hypertension in the rural population of Bangladesh. 


\section{References:}

1. Sayeed MA, Khan AR, Banu A, Hussain MZ. Prevalence of diabetes and hypertension in a rural population of Bangladesh. Diabetes Care 1995; 18: $555-558$.

2. Nissien A, Bothig S, Grenroth H, Lopez AD. Hypertension in developing countries. World Health Stat Q 1988; 41: 141-154.

3. Reddy KS. Hypertension control in developing countries: generic issues. J Hum Hypertension 1996; 10: 33-38.

4. Gupta R. Meta analysis of prevalence of hypertension in India. Indian Heart Journal 1997; 49: 43-48.

5. Hussain SA, Nayak KC, Gupta A. A study of prevalence of hypertension with reference to economic, educational, environmental and hereditary factors in general population of NorthWest Rajasthan. Indian Heart Journal 1988; 40:148-151.

6. Dutta BB. Studies on blood pressure, height, weight, chest and abdominal measurements of 2500 members of the Calcutta Police with short notes on their medical impediments. Indian Med Gazette 1949; 84: 238-243.

7. Sharma BK, Arora OP, Bhargha V, Sanghvi S, Purohit S. Prevalence of hypertension among the industrial workers and professional classes in Ludhiana, Punjab. Indian Heart Journal 1985; 37: 380-385.

8. Chobanion AV, Bakris GL, Black HR. The seventh report of the joint national committee on prevention, detection, evaluation, and treatment of high blood pressure. JAMA 2003; 289: 25602572. 